\title{
LA NUEVA LEY DE IMPUESTO A LA RENTA
}

\author{
por ALVARo ReNCORet B., Profesor de Dere- \\ cho Tributario en la Escuela de Economía \\ (Universidad de Chile).
}

Para formular un juicio crítico sobre la nueva Ley de Impuesto a la Renta, es decir, para pronunciarnos acerca de si ella ha representado o no un aporte de buena solución del problema tributario, en general, y -por tanto- un mejoramiento de nuestro mecanismo de tributación sobre la renta, en particular, es conveniente partir de la realidad conocida del régimen anterior y verificar o tratar de verificar si la reforma ha significado o no el remedio adecuado de sus vicios.

Hay concenso general acerca de que un régimen tributario justo $\mathrm{y}$ conveniente debe exhibir, como principal herramienta de exacción, al impuesto progresivo, personal, sobre la renta total.

¿Y qué podría decirse de nuestra anterior realidad tributaria, desde este punto de vista?

-En primer término, que ella no ofrecía un impuesto único general sobre la renta; sino -con el carácter de principal - un impuesto cedular, discriminatorio en cuanto al origen de la renta, y - con el carácter de complementario- el impuesto progresivo sobre la renta total.

La importancia del impuesto a la renta, dentro del conjunto de ingre- sos tributarios fiscales, podría apreciarse en las cifras correspondientes al año 1962, últimas que exhibió el señor Ministro de Hacienda, en la discusión parlamentaria de la reforma :

Según esas cifras, los impuestos sobre la renta - excluído el que afecta a las utilidades de la gran minería del cobre- representaron el $22,8 \%$ del conjunto de aquellos ingresos; el que pagaron las grandes empresas cupríferas, equivalió a un $13,6 \%$ del mismo conjunto.

Y, para apreciar la importancia del impuesto global complementario, dentro del mecanismo de la antigua Ley sobre Impuesto a la Renta, serán suficientes las siguientes cifras:

Del $22,8 \%$ de ingreso tributario, que dicha ley representó en el referido año de 1962, sólo el 1,9\% correspơndió al global complementario.

"El número de contribuyentes " afectos a este impuesto, decía el " señor Ministro, ha ido en constan" te disminución en los últimos “ años: es así como en 1956 dichos " contribuyentes llegaban a 119.346; " en 1962 el total de contribuyentes " al impuesto golbal complementa“ rio ascendió sólo a 38.264. 
"Del total de contribuyentes afec" tos a este impuesto en el año 1962, " sólo 401 contribuyentes declararon “ rentas líquidas superiores a 20 " sueldos vitales anuales. Por otra “ parte, 35.716 contribuyentes decla" raron rentas líquidas inferiores a “ 10 sueldos vitales anuales, y 2.066 “ contribuyentes declararon rentas " líquidas comprendidas entre $10 \mathrm{y}$ " 20 sueldos vitales anuales".

Podrían resumirse las causas de tan penosos resultados, mencionando:

$\left.1^{\circ}\right)$ La evasión ;

29) El régimen de presunciones rígidas o fijas, en vez de presunciones de rentas mínimas, que permiten inquirir para determinar rentas efectivas, muy a menudo, 'notoriamente superiores ;

$3^{\circ}$ La multiplicidad de disposiciones eximentes del pago de este impuesto, con fines de fomento, no siempre justificadas desde el punto de vista de los verdaderos intereses generales;

$4^{\circ}$ ) El aumento, a partir del año 1960 , de 1 a 3 sueldos vitales, del mínimo exento del impuesto global, etc.

¿Cuál ha sido la actitud de la reforma, frente a esta realidad?

Desde luego y en especial para prevenir irreparables sorpresas que en el rendimiento de ingresos fiscales pudiera producir un cambio demasiado brusco en cl sistema, no se. implantó de inmediato el impuesto único, progresivo sobre la renta total, aún cuando se expresó que ello constituía la meta a la cual se aspiraba llegar, en una segunda etapa de modificaciones.
Así y como un paso de transición, se convino en racionalizar, simplificándolo, el impuesto cedular; y poner más énfasis en el impuesto global complementario, haciéndolo de aplicación más general, en cuanto a las personas y en cuanto a las rentas que deben ser afectadas por él.

Vamos por partes, y refirámosnos primeramente a las modificaciones introducidas en materia de

\section{IMPUESTO CEDULAR}

Junto con referirnos a las disposiciones que, propiamente, constituyen el impuesto cedular - contenidas en el Título II de la nueva Ley- nos referimos a las "normas generales" - de que trata el Título I- entre las que hay algunas de real importancia.

El impuesto cedular, originalmente concebido y edificado sobre la base del principio de gravar más a las rentas fundadas que a las no fundadas, es decir, de gravar más a las rentas del capital que a las del trabajo, había llegado - a través de innumerables modificaciones circunstanciales- a perder toda armonía y a representar -en sus 6 cédulas o "categorías" - un conjunto arbitrario, en el cual, de aquel su principio básico, apenas si quedaban vestigios.

Basta, al respecto, recordar que las rentas del trabajo: sueldos (Quinta Categoría) y las provenientes del ejercicio de las profesiones liberales (Sexta Categoría) que en un comienzo - 1924- tuvieron iguales tasas de tributación, llegaron en 1963 a tributar en la proporción de $3,5 \%$ las primeras y $22,05 \%$ las segundas; tasa, esta última, superior a la que se aplicaba sobre dividendos de sociedades anónimas...

La nueva ley -orientada hacia la 
futura supresión del impuesto cedular- redujo las seis categorías a sólo dos, agrupando en la Primera a las rentas del capital y a las de empresas de cualquiera naturaleza; y en la Segunda, a las del trabajo.

Está bien haber incorporado las rentas de la propiedad inmueble a la tributación cedular; pero fue un paso atrás -en materia de justicia tributaria - haber abandonado el criterio antiguo, en cuanto a la estimación presunta del beneficio que para su propietario significa habitar casa propia y que consistía en una presunción más favorable para el ocupante de casa modesta. Discriminación elementalmente justa -de importantes efectos en el impuesto global complementario- como quiera que la habitación de escaso valor llena sólo una función primordial, en tanto que la vivienda de mayor confort o de lujo, supone el disfrute de satisfacciones de otra índole, cuyo logro debe ser razón para tributar en mayor medida.

Dentro del tratamiento de las empresas, ofrece novedades lo relativo a la tributación de las rentas originadas en sociedades anónimas. Materia en la cual la nueva ley ofreze contradicciones.

Por una parte y como expresión del sano propósito de equiparar el gravamen sobre las rentas provenientes de dichas sociedades, con el que se aplica a las que provienen de otros tipos de empresas, se ha suprimido el impuesto sobre los dividendos; en cambio, por otra parte. se recarga en un $50 \%$ la tasa aplicable a la sociedad misma, con lo cual se anulan los efectos de la medida anterior.

Se ha eliminado - justificadamente- la disposición que antes eximía del impuesto global comple- mentario a las rentas capitalizadas en empresas no pertenecientes a sociedades anónimas; en cambio, respecto de la capitalización de rentas en esta clase de sociedades y su distribución en forma de acciones liberadas, a los accionistas. se establece que para éstos esa distribución no constituye renta, lo cual se traduce en la no aplicación del impuesto global complementario respecto de esta forma de fruto o beneficio.

Hubiese sido más lógico, más justo y más simple tratar a todas las empresas y a todas sus rentas del mismo modo: para todas la misma tasa; que, en ninguna, la distribución de los beneficios entre los socios o accionistas sea motivo para aplicar impuesto cedular; que toda la renta ganada por empresa no pernecientes a sociedades anónimas sea afectada por el impuesto global, en las personas de los empresarios o socios, y que toda renta distribuida por la sociedad anónima a sus accionistas - sea en dinero o en forma de acciones liberadas - quede, igualmente, afectada por el impuesto complementario en las personas de los accionistas.

En relación con el impuesto cedular - sin embargo de no formar parte integrante de él y aún cuando, en verdad, no se trata de un tributo sobre la renta- consideramos oportuno referirnos aquí al impuesto con que la nueva ley grava a las llamadas "ganancias de capital"; las que, en términos generales, podríamos decir que consisten en incrementos patrimoniales, esencialmente esporádicos - pero, en oportunidades, de gran significación económica- y que, por aquella circunstancia, o sea, la falta de periodicidad, no tienen el carácter específico de "rentas".

Estos beneficios, de los cuales los 
más importantes son los que derivan de operaciones aisladas de adquisición y enajenación de bienes raíces, estaban al margen del impuesto sobre la renta; es verdad que el impuesto de timbres sobre los respectivos contratos llegó a representar un gravamen bastante fuerte sobre ellos.

La nueva ley aplica, sobre estas utilidades esporádicas, un impuesto único de tasa igual a la establecida para la Primera Categoría, en el impuesto cedular. Se dice "único", porque ellas no son afectadas por el impuesto global complementario, ni por el adicional.

En general y salvo algunos reparos de redacción, consideramos un acierto haber legislado sobre la materia, en el sentido que lo hace la nueva ley. Agreguemos, finalmente, que la idea de este gravamen se contenía en antigua proposición de ley, que no había prosperado en el Parlamento.

No sólo entre las disposiciones del impuesto cedular, sino a lo largo de toda la ley, se advierten vicios de redacción que, a veces, se traducen en obscuridad de pensamiento.

Así, por ejemplo, merece graves reparos la definición de "renta", contenida en el artículo $2^{\circ}$, en la cual aparecen lamentablemente confundidos conceptos, generalmente inconfundibles, como los de "ingresos" y "utilidades o beneficios", respecto de los cuales la propia ley distingue más adelante.

Peor, acaso, es la definición de "renta mínima presunta", con la agravante de que no era éste el concepto que había que definir - puesto que no aparece usado en parte al- guna de la ley- sino el de "renta mínima imponible", ya que hay disposiciones que presumen su existencia.

Definida la "renta mínima presunta" como "la cantidad que no es susceptible de deducción alguna por parte del contribuyente" ¿qué debe entenderse cuando - -en el artículo 20, para el caso de no acreditarse fehacientemente la renta efectivase dice que "el Servicio podrá pre" sumir que la renta mínima impo“ nible de dichos bienes es igual al " $7 \%$ de su avalúo respecto de los " bienes raíces no agrícolas y de “ $10 \%$ del avalúo de ellos, tratándo"se de predios agrícolas"?.

Parece que el Servicio no puede otra cosa que presumir ese $7 \%$ o ese $10 \%$, según el caso, y que el contribuyente no podrá hacer rebaja o deducción alguna de las cantidades representativas de esos porcentajes. Es decir, volvemos al sistema de presunciones fijas.

Distinto habría sido definir a la "renta mínima imponible" como "la " menor cantidad sobre la cual pue" de aplicarse el impuesto" y agregar: "Cuando en esta ley se presu" ma una "renta mínima imponible", el "contribuyente no quedará libe" rado de la obligación de tributar " sobre la renta efectiva, si ella fue"re mayor; en todo caso, al Servicio " corresponderá la obligación de exi"girlo".

En el artículo $6^{\circ}$ se habla de que, mientras no se determinen las cuotas de los comuneros en la comunidad hereditaria, se considerará a ésta como la continuación de la persona del causante.

Pero ¿cuándo puede ocurrir esto, si se tiene presente que las cuotas 
están siempre determinadas por la ley o por el testamento?

En el No 17 del artículo 17 se dice que no constituyen renta "Las sumas percibidas por concepto de "gastos de representación, siempre " que dichos gastos estén deterni“ nados legalmente o sean razona" bles, a juicio del Director".

$¿$ De manera que lo que la ley tiene que determinar son "los gastos"?

En el $N^{\circ} 8^{\circ}$ del mismo artículo 17 se dice que no gozan de la franquicia en él establecida los contribuyentes que hubieren hecho las operaciones que originan el ingreso, "a base de créditos".

¿Cuándo se entiende que una operación se ha hecho "a base de créditos"?

En el No $2^{\circ}$ del artículo 20 se consideran incluidas, entre las rentas de capitales mobiliarios, a las que provengan de "créditos de cualquiera clase"; el No $3^{\circ}$ del mismo artículo se refiere a las rentas de la industria y el comercio.

¿Dónde se clasifican los intereses provenientes de créditos tan genuinamente mercantiles como los originados por ventas a plazo, de mercaderías?

En el $\mathrm{N}^{\circ} 1$ del artículo 45, se declara al margen del impuesto global complementario, a las "devoluciones de fondos provenientes de ganancias de capital", hechas a sus accionistas, por una sociedad anónima en liquidación.

Si la ganancia de capital la ha hecho la sociedad, no puede hablarse de "devolución" de ella a los socios, porque sólo se "devuelve" algo a alguien cuando éste, previamente, lo ha entregado.
En la letra c) del artículo 50, se califica de "ganancia de capital" al mayor valor obtenido en la "enajenación de derechos, cuotas o acciones en una sociedad de personas, a una persona distinta de la sociedad". Pero, en la práctica ¿cuándo se ve que un socio le ceda su cuota o derecho a la sociedad misma? ¿Es que se ha querido decir "persona ajena a la sociedad"? ¿Qué razón habría para el distingo?

No se olvide que el tratamiento de una ganancia o beneficio, como "ganancia de capital" es un favor tributario, que consiste en no aplicar, respecto de dicho beneficio, el impuesto global progresivo sobre la renta total.

El artículo 74 establece que si alguien no prueba el origen de los fondos con que ha subvenido a sus gastos o realizado inversiones, se presumirá que corresponden a utilidades afectas al impuesto de la Primera Categoría y agrega, textualmente :

"Se gravarán, además, esas utili"dades con el impuesto a las com"pra-ventas de bienes corporales " muebles o a los ingresos compren“ didos en el artículo $7^{\circ}$ del Decreto “ $\mathrm{N}^{0}$ 2772, de 18 de Agosto de 1943, "según sea el giro principal de acti"vidad del infractor".

; De manera que el impuesto de compraventas o de cifra de negocios se aplicará a "las utilidades" que havan producido las operaciones ocultadas y no sobre el volumen de esas operaciones, que es Jo que constituye la base imponible de aquellos tributos?

Sólo hemos querido destacar alguna de las más graves deficiencias de redacción de la nueva ley. 
A continuación, refirámosnos suscintamente a la reforma, desde el punto de vista del

\section{IMPUESTO GLOBAL COMPLEMENTARIO}

¿En qué consiste el mayor énfasis, puesto por la nueva ley, en la tributación progresiva sobre la renta total?

Principalmente, en las siguientes medidas :

a) Substitución del sistema de determinación presuntiva de las rentas de la propiedad inmueble, por el de exigir que se tribute, como dice el No 1 del artículo 20, sobre la "renta efectiva" de dichos bienes.

Recuérdese, sin embargo, que hemos calificado como una reminiscencia del viejo sistema, a la dudosa presu'nción de renta mínima imponible - contenida en el citado precepto- relacionándola con la definición de "renta mínima presunta" dada en el artículo $2^{\circ}$.

b) Incorporación -de las rentas exentas del impuesto complementario- a la renta global, para los efectos de aplicar la escala progresiva, deduciendo del tributo que así resulte, el que se habría aplicado a aquellas rentas, aisladamente consideradas.

c) Modificación de la escala progresiva del impuesto, en forma que significa reducir -el mínimo de subsistencia, exento - a un sueldo vital anual, en vez de los tres que regían desde 1960. El mecanismo que contempla las cargas familiares, como razón de aumento del mínimo de subsistencia, está concebido en términos tales que los contribuyentes casados, que tienen dos o más hijos a su cargo, no experimenta mayor gravamen - por efecto de la nueva escala- que el que antes soportaban.

d) La forma misma de considerar las cargas familiares, que se traduce en que el alivio - por cada carga- sea igual para todos; y 'no mayor para los contribuyentes de rentas más altas, como acontecía antes.

Todas estas medidas nos parecen dignas de aplauso.

Pero, insistimos en lo dicho al tratar del impuesto cedular, en materia de tributación de las rentas provenientes de sociedades anónimas, en cua'nto no consideramos atinado haber excluido de la aplicación del impuesto global complementario, al valor de las acciones liberadas recibidas por los accionistas.

No prosperó, en la discusión parlamentaria del Provecto de Reforma, la idea de que los cónyuges no divorciados - aún cuando entre ellos exista separación de bienes- hagan una declaración conjunta qe sus rentas, para los efectos del impuesto global complementario.

Entre nosotros, es una realidad que la separación convencional se pacta, casi siempre, con la exclusiva mira de eludir la progresividad de este impuesto. Y es claro que ella sólo puede constituir una posibilidad aprovechable de evasión, para los contribuyentes que poseen bienes patrimoniales más o menos cuantiosos, productivos de rentas.

No es menos cierto que existe una separación legal de bienes respecto de las rentas que gana la mujer casada, cuando ejerce un trabajo separado del de su marido. De manera que los contribuyentes acaudalados pueden, con razón, decir que no sólo ellos, sino también los que obtie- 
nen rentas del trabajo, se ven favorecidos con el hecho de que los efectos de la separación de bienes lleguen hasta lo tributario.

\section{Indudablemente, es ásí.}

Pero ¿puede negarse que la situación económica de estos contribuyentes -ya sea que obtengan rentas del capital, ya sea que las obtengan del trabajo- es la que corresponde al total de ingresos de que disfrutan el marido y la mujer que viven juntos?

¿Y qué compensación tributaria tiene la mujer que trabaja -por ciento, sin sueldo $\mathrm{y}$ sin beneficios previsionales propios- en la atención y cuidado de su hogar? Es decir, aquella mujer que - por no permitírselo el número, la edad o la salud de sus hijos- no puede ejercer una profesión o procurarse un sueldo que, frecuentemente, se gana con harto menos sacrificio que el que demanda el trabajo doméstico?

Creemos que debe llegarse a la declaración conjunta de los cónyuges no divorciados y que las rentas de ambos - sea que provengan del capital o del trabajo- deben ser afectadas, como un solo todo, por el impuesto progresivo sobre la renta total.

Igualmente, consideramos lamentable que el Parlamento no acogiera, en los términos en que el Proyecto del Ejecutivo la sugería, la publicidad del rol de contribuyentes del impuesto global complementario.

Mientras el Proyecto proponía una "amplia publicidad" en el Diario Oficial u otro diario de general circulación y que el Director de Impuestos Internos podría, además, disponer la publicación o publicidad de las listas completas de contribuyen- tes del impuesto global complementario, mediante otros medios, en definitiva la ley sólo aceptó que en cada una de las Inspecciones del Servicio se mantuviese a disposición del público, "una lista en que apa" rezcan por orden alfabético los " nombres de todos los contribuyen"tes afectos a los impuestos de la " presente ley, de acuerdo con las de"claraciones anuales que deben pre" sentar en virtud del artículo 67".

No es difícil imaginar la ineficacia de semejante disposición, cuyo texto parece orientado a disimular a los contribuyentes del impuesto global complementario entre la multitud de "todos los contribuyentes afectos a los impuestos de la presente ley".

Estamos íntimamente convencidos de que una medida como la que el Proyecto proponía es indispensable para lograr un efectivo saneamiento tributario nacional.

La represión del fraude, la necesidad urgente de reducir la evasión en medida apreciable, no es sólo un problema fiscal; antes que fiscal, es un problema de los propios contribuyentes, de esos que pueden - con razón- hablar de fatiga tributaria, mientras que existen muchos que distan de sentirla. Los impuestos que se eluden influyen en el costo de la vida, en la misma forma que los que se pagan. porque quienes los eluden no prescinden de ellos al fijar los precios de sus productos o de sus servicios. Pero, no sólo significan beneficio exclusivo para el que los burla, sino que -por añadidura- la sustracción de ellos al Erario debe ser suplida por mayor aporte de los que siempre pagan.

De aquí que no pueda negarse a la masa contribuyente el derecho a informarse, directamente y por sí misma, de si la legislación tributaria 
se cumple o no en forma de hacerse efectivo el precepto constitucional sobre justa repartición de la carga.

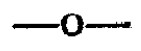

Es temprano aún para apreciar si la reforma ha producido o no, efectivamente, los resultados que de ella se esperaban. Y si, en algunos aspec-

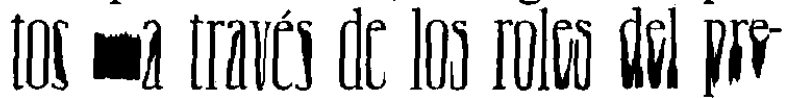
sente año- pudiera ya barruntarse algo, lo cierto es que los organismos oficiales correspondientes aún no han informado al país sobre el particular.

En todo caso, tengamos presente que en el logro o en el fracaso de las esperanzas cifradas en la reforma tributaria, debe jugar un factor de muy alta significación, ajeno al tenor mismo de la ley. Ese factor es la Administración, a la cual pertenecerán, también en alta medida, los honores del buen éxito o las responsabilidades de la desilusión.

Siempre está vigente el consejo que, al Gobernador de la ínsula Barataria, daba el ilustre manchego:

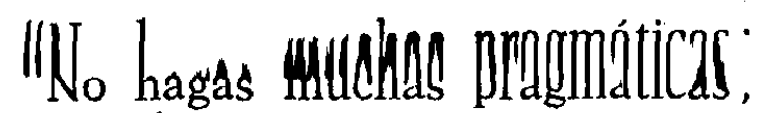
"si las hicieres procura que sean " buenas y, sobre todo, que se cum" plan; que las pragmáticas que no " se guardan lo mismo es que si no "lo fuesen; antes, dan a entender " que el príncipe que tuvo discreción "y autoridad para hacerlas no tuvo "valor para hacer que se guarda"sen".

\section{EL IMPUESTO DE CIFRA DE NEGOCIOS Y SU RELACION CON LA DESAPARECIDA TERCERA CATEGORIA DE LEY SOBRE IMPUESTO}

\section{A LA RENTA}

El artículo $7^{\circ}$ de la Ley $\mathrm{N}^{\circ} 15.564$, llamada de "reforma tributaria". que fijó un nuevo texto a la Ley sobre Impuesto a la Renta, dispone lo siguiente, en su inciso primero:

"No obstante la eliminación que " por esta ley se hace de la Tercera “ Categoría de la Ley sobre Impues. " to a la Renta, el impuesto de cifra “ de negocios establecidos en el ar“ tículo 7\% del Decreto de Hacienda “ $\mathrm{N}^{\circ}$ 2772, de 18 de Agosto de 1943, “ seguirá afectando a los mismos in" gresos que actualmente se gravan " con dicho impuesto y bajo las mis" mas reglas y condiciones señala" das en la disposición aludida".

Recuérdese que el Decreto № 2772 - dictado en virtud de facultad especial, concedida por la Ley número 7.200, al Presidente de la República- refundió diversos textos legales relativos, entre otros, al impuesto de cifra de negocios.

Una disposición semejante a la que hemos transcrito, era necesaria en la Ley $N^{\circ} 15.564$, por cuanto ella redujo a dos, las antiguas seis categorías del impuesto cedular sobre la renta, y por cuanto el impuesto de cifra de negocios - según lo dispone el artículo 7 ${ }^{\circ}$ del Decreto de Hacienda $\mathrm{N}^{\circ} 2772$ - deben pagarlo las personas naturales o jurídicas que, "por “ razón de negocios, servicios o " prestaciones de cualquiera espe" cie, perciban intereses, primas co" misiones u otras formas de remu" neración, siempre que las sumas " percibidas por tales conceptos " constituyan ingresos sujetos a “ las disposiciones de la Tercera

" Categoría de la Ley sobre Impues"to a la Renta". Por manera que 
-reducidas sólo a dos, las categorías del impuesto cedular sobre la renta- ningún ingreso quedaría, en adelante, "sujeto a las disposiciones de la Tercera" $y$, consecuencialmente, el impuesto de cifra de negocios habría sido tácitamente dercgado, sin quererlo.

Pero, el Legislad'or no fue feliz al redactar la disposición del artículo $7^{\circ}$ de la Ley N: 15.564 -que hemos transcrito-y consideramos que su letra traiciona la intencióni con que fue dictada.

Desde luego ,el precepte alude "a los mismos ingresos que actualmente se gravan con dicho impuesto", en circunstancias qu $\in$ quiere referirse a los ingresos que se gravaban en el imperio de la antigua ley sobre impuesto a la renta - derogada por la propia Ley 15.564 - y que, por lo mismo, ya no pertenece a la "actualidad", sino al pasado.

Por consiguiente -en vez de hablar de "ingresos que actualmente se gravan" - debió hablarse de "ingresos que se gravaban con anterioridad a la dictación de la presente ley".

Supơngamos que así está dicho.

Pero ¿qué significa decir que el impuesto de cifra de negocios "seguirá afectando a los mismos ingresos que actualmente se gravan con dicho impuesto $\mathrm{y}$ hajo las mismas reglas $\mathrm{y}$ condiciones señaladas en la disposición legal aludida"?

Literalmente, parece significar que todos los ingresos que, bajo el imperio de la antigua ley sobre impuesto a la renta, se clasificaban dentro de la Tercera Categoría, seguirán considerándose clasificados en ella, para los efectos de aplicar el impuesto de cifra de negocios. En otras palabras, la antigua Tercera Categoría se consideraría subsistente, para tales efectos. $Y$ no sólo subsistentes; sino, además, incluyendo en sus preceptos a los mismos ingresos que antes incluía.

Ello estaría bien siempre que la reforma tributaria ,al darle una nueva estructura al impuesto cedular sobre la renta, se hubiese limitado a fundir las antiguas primeras cuatro categorías, en la nueva Primera, y las últimas dos antiguas, en la nueva Segunda. Es decir, si en esta materia, se hubiese limitado, exclusivamente, a ubicar a la antigua Tercera Categoría dentro de la nueva Primera, "sin tocarla", o sea, manteniendo dentro de ella a los mismos ingresos que la antigua ley sobre impuesto a la renta sujetaba a sus disposiciones.

Pero, ocurre que la ubicación de la antigua Tercera Categoría, dentro de la nueva estructura del impuesto cedular, no es hizo "sin tocarla"; por el contrario, la nueva ley alteró substancialmente el tratamiento de ciertos ingresos dentro del impuesto cedular y algunas de estas alteraciones equivalen a haber sacado a determinados ingresos del régimen de la antigua Tercera Categoría, en forma que actualmente ellos no se clasificarían dentro de dicha cédula, suponiéndola existente.

Por ejemplo: se sabe que, a virtud de lo que disponía el antiguo artículo 13 de la ley sobre impuesto a la renta, tributaban en Tercera Categoría los ingresos obtenidos por sociedades de profesionales (abogados, ingenieros, etc.), de donde resultaba que los honorarios que estas sociedades percibían, en razón de los servicios profesionales que dispensaran sus socios, se gravaban con el impuesto de cifra de negocios. 
Ahora bien, la nueva ley sobre impuesto a la renta, según el texto fijado por la propia Ley $N^{\circ} 15.564$, dispone que tributarán en la Segunda Categoría (que es la que resume a las antiguas Quinta y Sexta )los "in" gresos obtenidos por sociedades “ de personas que presten exclusiva" mente, servicios o asesorías profe" sionales por intermedio de sus so" cios o asociados. En este último “ caso se considerarán como contri" buyentes, para todos los efectos " de esta ley, a dichos socios o aso" ciados, a prorrata de su participa“ ción en las utilidades sociales".

¿Podría pretenderse aplicar cifra de negocios a los honorarios que, en el imperio de la nueva ley sobre impuesto a la renta, perciba una sociedad de profesionales, so pretexto de que antes eran afectados por aquel tributo, en cuanto "ingresos sujetos a las disposiciones de la Tercera Categoría"?

No vacilamos en pronunciarnos negativamente, por cuanto si, dentro de la ley sobre impuesto a la renta, la de reforma tributaria no hubiese introducido otra modificación que la de eliminar a las sociedades de profesionales de entre los contribuyentes de la Tercera Categoría, automáticamente dichas sociedades -y por ese sólo hecho- habría quedado al margen del impuesto de cifra de negocios.

$\mathrm{Y}$ es inadmisible sostener que ese efecto deja de producirse por el mero hecho de que - aparte de esta modificaciớn substancial se haya introducido otra de forma, consistente en reducir a dos las antiguas seis categorías del impuesto cedular.

Para que las alteraciones substanciales introducidas por la nueva ley sobre impuesto a la renta -en materia de clasificación de los ingresos dentro de las diversas categoríasno surtieran efecto frente al impuesto de cifra de negocios, hubiera sido necesario que la. Ley $\mathrm{N}^{\circ} 15.564$ lo hubiese establecido expresamente; y lo cierto es que no lo hizo.

Más aún: no solamente no lo hizo, sino que expresó que el impuesto de cifra de 'negocios seguiría aplicándose "bajo las mismas reglas y condiciones señaladas en la disposición legal aludida", o sea, en el artículo $7^{\circ}$. del Decreto de Hacienda No 2772 que pone, como condición para gravar un ingreso con el impuesto que él establece, la de que ese ingreso "esté sujeto a las disposiciones de la Tercera Categoría". De manera que si alguna ley se dicta, que signifique sustraer a determinado ingreso de lo que antes constituía la Tercera $\mathrm{Ca}$ tegoría, ello determina que en dicho ingreso deje de cumplirse la más importante de las condiciones exigidas por el referido artículo $7^{\circ}$ del Decreto 2772.

Otro caso interesante de aplicación del artículo $7^{\circ}$ de la Ley de Reforma Tributaria, puede presentarse con ocasión de que alguna sociedad anónima, al emitir nuevas acciones, reciba de los suscriptores de éstas un valor superior al nominal de las mismas.

Ese mayor valor (premio o prima) siempre fue considerado, por Impuestos Internos, como ingreso sujeto a las disposiciones de la Tercera Categoría y, en consecuencia, exigió que, respecto de él, se pagara el impuesto de cifra de negocios. La jurisprudencia de los Tribunales Superiores fue favorable a esta tesis en diversas ocasiones; en otras no.

¿Podría el Servicio de Impuestos Internos seguir sosteniendo esta misma doctrina y aplicar el impues- 
to de cifra de negocios, sobre el monto del premio o prima que una sociedad anónima obtenga al hacer una nueva emisión de acciones?

Tampoco lo cremos; por el contrario, pensamos que el problema ya no puede plantearse, en razón de que ahora es indiscutible que tal ingreso no puede ser afectado por el impuesto de cifra de negocios. Ello, porque la nueva ley sobre impuesto a la renta, al declarar que dicho ingreso es uno de los que "no constituyen renta" (artículo 17, № $5^{\circ}$ ) lo sustrajo del campo de aplicación del impuesto cedular $\mathrm{y}$, por consiguiente, ahora no está "sujeto a las disposiciones" que antes configuraban la Tercera Categoría.

Si la intención del Legislador hubiese sido la de "congelar" la clasificación de los ingresos dentro de la Tercera Categoría, en los mismos términos en que ella se encontraba antes de la dictación de la ley de reforma tributaria, se habría limitado a decir que este impuesto "seguirá afectando a los mismos ingresos que actualmente se gravan con dicho impuesto" (o "que se gravaban", como cree el suscrito que debió decirse) y nada más. Pero, agregó: "bajo las mismas reglas y condiciones señaladas en la disposición aludida" (artículo $7^{\circ}$ del Decreto 2772) lo que -literal y estrictamente considerado- es contradictorio con la primera parte de la oración, porque equivale a decir;

No sbstante la eliminación de la Tercera Categoría, el impuesto de cifra de negocios seguirá afectando a los "ingresos sujetos a las disposiciones de la Tercera Categoría" (ya que esto es lo que dice el artículo $7^{\circ}$ del Decreto 2772) en circunstancias que dicha Categoría ha sido "eliminada" $y$, por tanto ya no existe...
La única interpretación racional del precepto en examen consistiría en suponer que lo que se ha querido decir es que el impuesto de cifra de negocios se aplicará, en adelante, sobre "intereses, primas, comisiones u otras formas de remuneración siempre que las sumas se perciban por tales conceptos constituyeran ingresos sujetos a las disposiciones de la Tercera Categoría, si dicha cédula existiera" y salvas --naturalmentelas exenciones que por diversas leyes se han establecido, ya que si esto no se da por subentendido, habría que convenir en que todas las exenciones del impuesto de cifra de negocios han quedado derogadas, toda vez que el art. $7^{\circ}$ de la Ley 15.564 sólo se remite a "las reglas y condiciones señaladas" en el artículo $7^{\circ}$ del Decreto 2772 y éste no establece exención alguna... Y salvas, también, las normas que, a partir de la propia Ley $\mathrm{N}$ ? 15.564 inclusive, el Legis \ador tenga por conveniente dictar y que signifiquen sustraer a determinados ingresos del régimen de la ex Tercera Categoría o someter a él, a otros que antes no lo estaban.

Ahora bien, si existiera la Tercera Categoría iestarían sujetos a ella los ingresos obtenidos por una sociedad de profesionales, de aquellas a que se refiere el $\mathrm{N}^{9} 2^{\circ}$ del artículo $36 \mathrm{de}$ la nueva Ley sobre Impuesto a la Renta, o los obtenidos por una sociedad anónima, a título de premio o prima de acciones de su propia emisión?

Evidentemente que nó : los primeros, porque dichas sociedades están ahora tratadas del propio modo que los profesionales mismos (antigua Sexta Categoría) y los segundos, porque ahora dichos ingresos no son reputados renta $y$, por tanto, mal podrían estar sujetos a las disposiciones de la ex Tercera Categoría o 
de cualquiera otra.

Por consiguiente, respecto de ninguno de estos ingresos se cumplirían "las reglas y condiciones señaladas" en el artículo $7^{\circ}$ del Decreto 2772 para estar sometidos al impuesto que dicho artículo establece, es decir, el de cifra de negocios.

Es lamentable que la redacción descuidada de nuestras leyes tributarias, vaya asumiendo las proporciones de una verdadera y sobresaliente característica de ellas.

Ejemplos de este grave mal, son las siguientes referencias a otras disposiciones legales, contenidas en el artículo 59 del nuevo texto de la Ley sobre Impuesto a la Renta y en los artículos 128 y 140 de la Ley número 15.575 , modificatorios de aquel texto.

El inciso $1^{\circ}$ del referido artículo “ 59 dice: "Sin perjuicio de lo dis" puesto en los incisos segundo, “ tercero y último del artículo $50 \mathrm{y}$ “ en el artículo 6 ${ }^{\circ}$ de la ley que mo“ difica las leyes de Impuesto a las "Herencias, Asignaciones y Dona“ ciones y a la Renta, estará exento “ de los impuestos de este Título el " mayor valor que se obtenga en la " enajenación de:"

¿Es propio citar o referirse a una ley de esta manera? ¿Cuántas leyes hay, que han modificado a la vez, a las dos mencionadas?

Pero, admirémosnos: "la ley que modifica las leyes", etc. parece ser la propia ley dentro de cuyo cuerpo está el artículo 59 que contiene la cita...

Hay más : el precepto referido habla de "los impuestos de este Título" y este Título establece un sólo impuesto, el llamado "a las ganancias de capital"...

Los artículos 128 y 140 de la Ley No 15.575 ordenan modificaciones al texto "del artículo 61 de la Ley número 15.564" y "del artículo 35 de la Ley $\mathrm{N}^{\circ} 15.564 "$; en circunstancias que esta ley sólo tiene 23 artículos permanentes y 5 transitorios...

Podrá decirse que "hay que entender que el Legislador quiso referirse" a los artículos 61 y 35 de la Ley sobre Impuesto a la Renta, cuyo texto se fijó en el artículo 5\% de la Ley $N^{\circ} 15.564$; pero, también habría que aceptar que tal sistema de legislar y aplicar la ley, conduce al desprecio de elementales principios jurídicos, al abandono de normas primarias de hermenéutica y a la irresponsabilidad de quienes intervienen en la proyección, aprobación y promulgación de las leyes. 